\title{
Hypothalamic Gangliocytoma
}

National Cancer Institute

\section{Source}

National Cancer Institute. Hypothalamic Gangliocytoma. NCI Thesaurus. Code C45918.

A tumor characterized by the presence of mature ganglion cells and neuronal

differentiation, arising in the hypothalamus. It is often associated with the presence of

pituitary gland adenomas. Symptoms include acromegaly and precocious puberty. 